\title{
USO DE PLANILHAS ELETRÔNICAS COMO FERRAMENTA PARA REDUÇÃO DA DISTÂNCIA TRANSACIONAL: PERCEPÇÃO DOS ESTUDANTES DA DISCIPLINA DE ESTATÍSTICA
}

SÃO PAULO/SP MAIO/2018

\author{
Lourdes Souza Utrilla da Silva - UAM - lourdes.utrilla@uol.com.br \\ Augusto Takerissa Nishimura - Laureate - augusto.nishimura@usp.br
}

Tipo: Relato de Experiência Inovadora (EI)

Categoria: Pesquisa e Avaliação

Setor Educacional: EDUCAÇÃO SUPERIOR

\begin{abstract}
RESUMO
A teoria da Distância Transacional é estudada especialmente no âmbito da Educação a Distância. Entretanto, apesar de não ser um assunto recente, ainda pouco se discute sobre o tema. O objetivo desse estudo foi conhecer os efeitos da implantação de planilhas eletrônicas como ferramenta de ensino na disciplina de estatística, oferecida na modalidade EaD de uma IES privada, sob a ótica da Distância Transacional. Para tanto, é apresentada uma modelagem de artefato pedagógico ajustado, visando estabelecer a proximidade comunicacional para reduzir a distância transacional, aplicada a uma disciplina. Foi considerada a relação entre os três elementos da distância transacional, quais sejam, estrutura, diálogo e autonomia, a partir do ponto de vista dos estudantes da disciplina estudada. Os resultados mostraram que o uso da planilha eletrônica, disponibilizado no Ambiente Virtual de Aprendizagem, incentiva o estudante quanto à elaboração, interpretação e construção de tabelas e gráficos, melhorando seu desempenho acadêmico e levando à redução da Distância Transacional. Como implicação para a prática, os resultados contribui ao indicar uma alternativa que vise facilitar o processo de ensino e aprendizagem.
\end{abstract}

Palavras-chave: Educação a distância; Planilha eletrônica; Distância Transacional, Ambiente Virtual de Aprendizagem e Estatística. 


\section{INTRODUÇÃO}

Na modalidade $E A D$, essa distância física entre discentes e docentes pode gerar ruídos comunicacionais entre instrutor e aluno, impondo um desafio ao engajamento dos estudantes nas atividades do curso. A prerrogativa é de que, apesar da existência dessa distância física, a redução da distância psicológica por meio de uso de ferramentas comunicacionais e artefatos educacionais é determinante para o engajamento e desempenho dos estudantes nessa modalidade.

Com o avanço das tecnologias, o uso de softwares tornou-se um artefato pedagógico relevante, além de facilitar a inclusão digital (Borba, 2005). Pela sua importância como estratégia didática, o uso dos artefatos pode fomentar a interação entre estudante e professor, mediando a comunicação e facilitando a aplicação das metodologias de ensino.

A partir do exposto, esse trabalho teve como objetivo estudar os efeitos da implantação de planilhas eletrônicas como ferramenta de ensino na disciplina de estatística EaD.

A premissa é de que a utilização de atividades práticas, por intermédio do uso de planilhas eletrônicas, facilitam o processo de ensino-aprendizagem por meio do aprender fazendo e, ao mesmo tempo, engajam os estudantes na resolução das atividades proposta, estimulando o canal de comunicação e reduzindo a distância transacional.

O estudo justifica-se, pois o uso de planilhas eletrônicas é um desses artefatos que podem ser utilizados como estratégica didática, pelo fato de ser amplamente difundida e utilizada para os mais diversos fins. Dania \& Posey (2012), Chong, Puteh \& Goh (2013) e Mays (2015) afirmam que as planilhas eletrônicas são reconhecidas como uma poderosa ferramenta de resolução de problemas no ensino, pois são controladas por regras e seu uso requer uma compreensão conceitual do assunto pelo usuário. Devido ao grande volume de dados disponíveis, a análise e interpretação de dados tornou-se uma habilidade importante no mundo do trabalho, pois o uso da ferramenta para o armazenamento e análise de dados é uma das competências requeridas para o suporte à tomada de decisão. O uso de planilhas permite a manipulação das funções, construção de tabelas e fórmulas, podendo ser explorado temas do cotidiano dos estudantes de forma interativa. 
A Educação a Distância faz parte o mundo da educação e os professores que atuam nessa modalidade podem fazer uso da teoria e da prática da educação convencional. A Educação a Distância tem como pano de fundo a teoria da Distância Transacional, que é composta por três grupos de variáveis, o Diálogo, a Estrutura e a Autonomia do estudante. A estrutura do programa é importante para manter uma boa comunicação entre professores-tutores e alunos e dessa forma reduzir a distância transacional (Moore, 1993).

Os programas de educação podem ser estruturados de diferentes formas, com estratégias flexíveis ou rígidas, considerando a necessidade de produzir, copiar, transmitir e controlar a mediação das mensagens. Em programas com pouca distância transacional os materiais didáticos precisam ser bem estruturados, porém poderá ter uma grande distância transacional se houver defasagem no diálogo entre docente e discente (Moore, 1993).

No âmbito da Educação a Distância, é o discente e não o docente quem determina como será o processo de aprendizagem. A autonomia do estudante é definida como a medida pela qual os estudantes assumem o protagonismo no âmbito do processo ensino-aprendizagem (Moore, 1993).

As novas tecnologias digitais conduziram à expansão do processo de aprendizagem, combinando recursos tecnológicos com humanos. No estudos sobre a Educação a Distância (EAD) argumenta-se que não há delimitação geográfica para o estudante frequentar uma sala de aula virtual, porque o uso de tecnologias digitais inovadoras permitiu ampliar a EAD no Brasil e no mundo (Lorençatto \& Carvalho, 2011).

Como legado, a tecnologia integrou espaços e tempos, ou seja, mundo físico e mundo digital, permitindo a interligação constante entre o ensinar e aprender. Assim, não são mundos ou espaços diferentes, mas a expansão de um espaço ou de uma sala de aula. Talvez por este motivo a sala de aula convencional se encontre cada vez mais híbrida, porque mistura o espaço físico com o virtual e cabe ao professor se comunicar tanto pessoalmente como digitalmente com os estudantes para manutenção do equilíbrio na interação (Moran, 2015).

No ambiente de aprendizagem virtual - AVA o estudante encontra os materiais necessários para a compreensão do conteúdo das respectivas disciplinas, tais como: atividades avaliativas, notas, agendamento de provas, avisos, além do acesso aos artefatos que permitem a aprendizagem colaborativa e a comunicação com o professor, tutor e outros estudantes da sua sala virtual. Esse ambiente apoia o estudante 
constantemente em qualquer local, 24hs por dia, 7 dias por semana (Phungsuk, Viriyavejakul \& Ratanaolan, 2017).

No contexto dessa pesquisa, para contribuir para o processo ensino-aprendizagem na disciplina de estatística para gestores, foram desenvolvidas planilhas do software Microsoft Excel $\AA$ de tal forma que o estudante possa desenvolver as principais atividades da disciplina de estatística para gestores aplicando a teoria na prática. Segundo Saraiva (2015), a Estatística ultrapassa um simples conjunto de dados utilizados como exemplo para o Censo Demográfico. Assim, pode ser considerada uma Ciência que estuda os processos de coleta, organização, análise e interpretação de dados que são relevantes em uma investigação.

Para isso, o arquivo da planilha eletrônica em excel foi inserido em uma das unidades de estudos da disciplina, contemplando os seguintes conteúdos: Tabelas, gráficos, tipos de amostragem e probabilidade. No início de cada atividade, são mencionadas as orientações para construção da atividade com um exemplo, conforme figura 1:

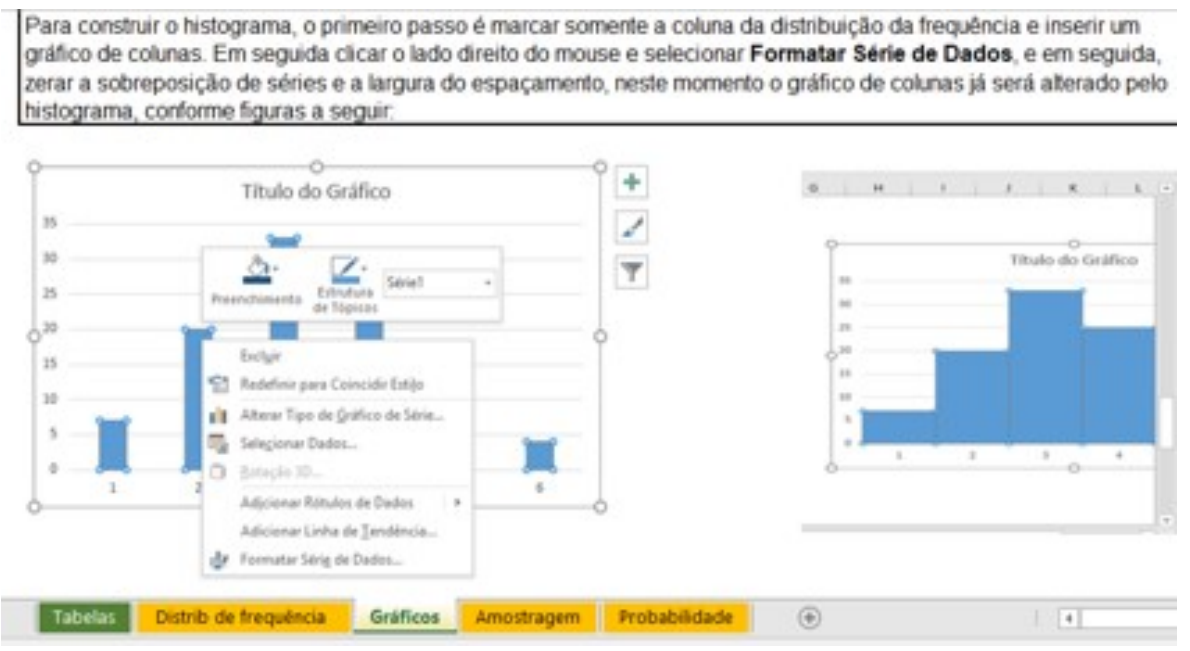

Figura 1. Planilha referente aos Gráficos

Para realização das atividades referentes aos gráficos, os estudantes precisam construir os gráficos e interpretá-los, para responder as questões objetivas da unidade de estudos dessa disciplina, conforme figura 2. 


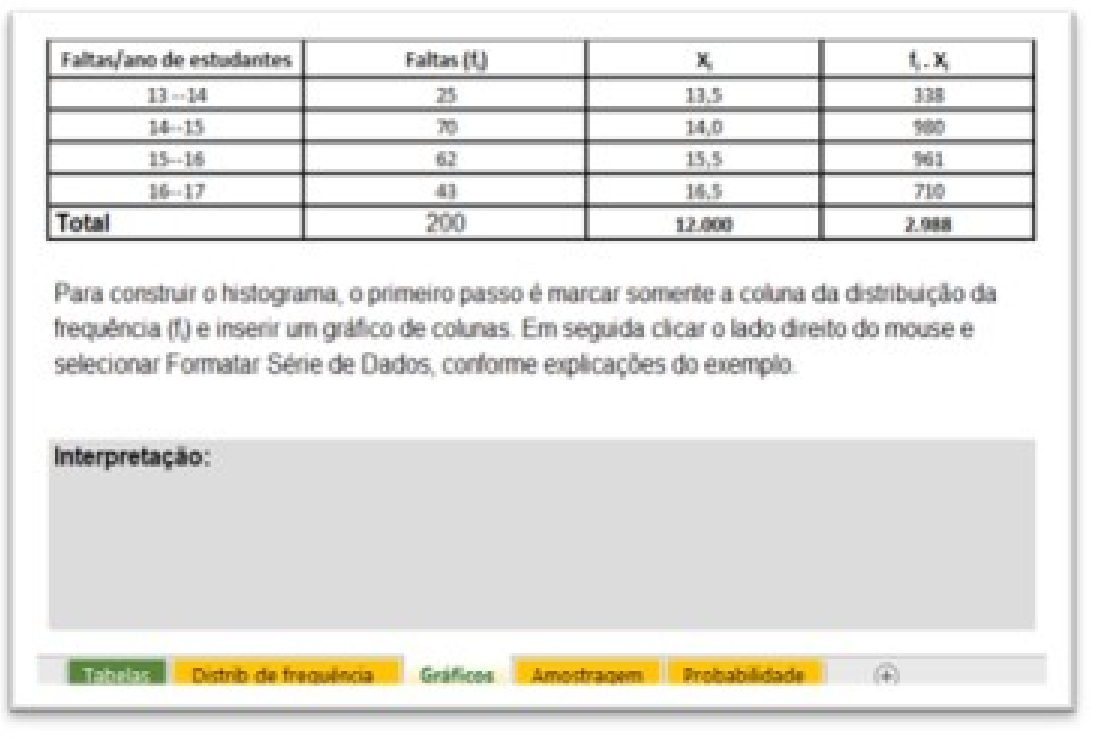

Figura 2. Planilha referente aos Gráficos com uma proposta de atividade

Com a implementação das planilhas eletrônicas, vislumbramos que os estudantes ao aplicar a teoria na prática, externem sua autonomia, assimilando os conceitos previstos no conteúdo das disciplinas.

\section{ASPECTOS METODOLÓGICOS}

Esse estudo possui abordagem qualitativa, pois, segundo Minayo (1994), nesse tipo de pesquisa o pesquisador tem o contato direto com o ambiente onde se desenvolve 0 estudo, os dados são coletados a partir de descrições de pessoas, situações, acontecimentos, incluindo-se transcrições de entrevistas, depoimentos e outros.

O estudo é caracterizado como pesquisa-ação, que pode ser aplicada em qualquer processo sistêmico de acordo com a proposta de estrutura em quatro etapas do ciclo proposto por Tripp (2005): identificar o problema, planejar uma possível solução, analisar a implementação da ação e avaliar se houve eficácia ou se existe a necessidade de melhorias da ação.

A população dessa pesquisa foi composta por todos os 1.712 estudantes ativos, matriculados na disciplina de estatística para gestores, oferecida na modalidade EaD, de cursos de nível superior em uma IES privada.

Para coletar os dados, foi realizada uma pesquisa tipo Survey com escala Likert de 5 pontos. As questões da pesquisa, desenvolvidas por Dania \& Posey (2012), foram adaptadas e aperfeiçoadas à realidade brasileira para permitir um melhor entendimento 
sobre a percepção dos estudantes da disciplina de contabilidade geral sobre o uso da planilha eletrônica.

\section{RESULTADOS E DISCUSSÃO}

Num primeiro momento, foi realizado o levantamento da situação problema na disciplina, avaliando as mensagens do fórum fale com o professor no segundo semestre de 2016, que é um canal disponível para que os estudantes possam postar dúvidas e questões acerca da disciplina. Foram identificadas uma quantidade relevante de estudante relatando dificuldades na compreensão do conteúdo.

Do universo de 1.712 estudantes matriculados na disciplina de estatística para gestores, no segundo semestre de 2017, 239 (14\%) responderam à pesquisa. Os resultados desse estudo evidenciaram a preferência dos estudantes pelo uso de planilhas no ensino de estatística para gestores. As opiniões foram refletidas no resultado das notas atribuídas pelos respondentes, considerando a escala likert de 1 a 5 , de Ruim a Excelente na figura 3:

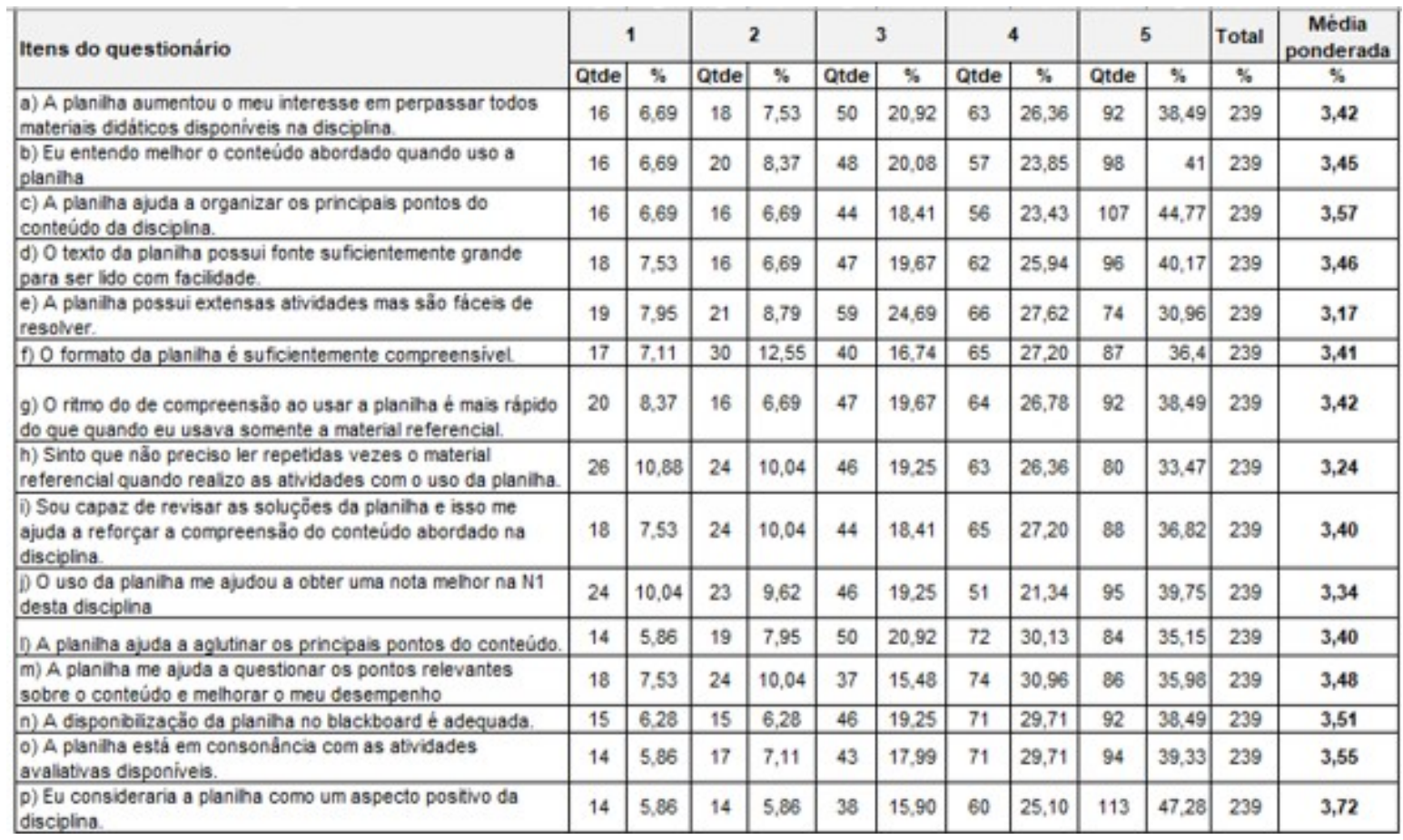

Figura 3 - Questionário utilizado na pesquisa sobre o uso das planilhas

Fonte: Adaptada de "Accounting Students Opinions towards use of Spreadsheets as an Instructional Tool " de Dania, A. \& Posey C., 2012; “ Journal Of Business, Industry, and Economics. Vol. 17". 
A pesquisa junto aos estudantes revelou que o uso da planilha auxilia na redução da distância transacional, com a identificação da existência dos elementos fundamentais para reduzir a distância transacional: Diálogo, Estrutura e Autonomia do estudante.

Ao definir a Teoria da Distância Transacional Moore (1993) assevera que o Diálogo Educacional é desenvolvido por meio interação com qualidades positivas entre docentes e discentes, e que a distância geográfica não é sinônimo de distanciamento no processo de aprendizagem. O diálogo pode ser utilizado de variadas formas, conforme a personalidade do professor, do estudante e também de acordo com o conteúdo, sendo essenciais para reduzir a distância transacional (Moore, 1993). Nos exemplos a seguir são evidenciados esses diálogos:

\footnotetext{
"Minha sugestão é que continuem com essa proposta em todas as matérias. Tanto em estatística quanto em contabilidade essa estratégia foi muito boa. Consegui fixar o conteúdo muito mais do que ficar horas lendo a teoria e continuar sem entender".
}

"Resolver os problemas a distância significa uma aula gradual excelente, assim buscamos corrigir os problemas, principalmente estudantes com extrema dificuldade em Exatas".

O cuidado com os elementos da estrutura da disciplina, são fatores determinantes para a adequada comunicação entre docentes e discentes, tendo como consequência o melhor aproveitamento por parte dos estudantes, além de sucesso para est modalidade de ensino (Moore, 1993). A pesquisa junto aos estudantes revelou a aprovação dos estudantes quanto a estrutura da disciplina de estatística para gestores EaD:

\begin{abstract}
"A planilha é fantástica! Fácil entendimento, e principalmente permite aprendermos na teoria, colocamos na prática com o uso da planilha. Deveria ter em todas as unidades para melhor aprimoramento do conteúdo". "As planilhas são maravilhosas. Práticas, rápidas, fácil compreensão, menos mecânica e mais objetiva que o material referencial. Não retirem esse método complementar de ensino". "Eu aprovo o uso de planilhas nas matérias que utilizam quaisquer tipos de cálculos pois nela é possível aprendermos na prática o que muitas vezes não compreendemos somente com a leitura do material referencial". "Foi muito mais fácil entender o conteúdo, ao utilizá-lo na planilha do que no próprio material didático, pois no material não temos um uso prático da atividade". "Excelente material, simples e objetivo. Me ajudou muito e gostaria que tivesse nos próximos semestres. Fica mais dinâmico". "Eu creio que para as disciplinas complexas como Contabilidade, Custo e Estatística, o uso da planilha é fundamental, pois o curso a distância precisa do máximo de clareza possível por meio de material, para um melhor entendimento das disciplinas". "Está ótima assim bem esclarecida, ela nos ajuda muito a fixar o conteúdo".
\end{abstract}

De acordo com Moore (1993), a autonomia normalmente está presente na educação a distância por tratar-se modalidade voltada para o estudante adulto e, por conta disso, acredita-se na sua capacidade de tomar decisões. Mas o fato é que nem todos os adultos são iguais, e por conta disso, é necessária a intervenção, no sentido de motiválos para que eles externem sua autonomia. 
"O fato de ter uma atividade exemplo já resolvida antes da atividade que devemos responder facilita muito o entendimento. Toda a matéria fez sentido depois dos exercícios e com o exemplo a ser seguido refrescou a memória de como resolver, sendo uma ótima forma de conseguirmos corrigir de forma autônoma os nossos exercícios, baseando-nos pelo exercício de exemplo". "Quando comecei a estudar a disciplina, fiquei muito assustado com todo aquele material referencial, mas assim que a professora comentou na WEB conferência, que tínhamos a planilha para ser preenchida, percebi que era somente prestar atenção e ir preenchendo conforme $o$ enunciado e ficou bem mais fácil a compreensão da matéria. Caso não tivesse a disponibilização da planilha, acredito que seria bem mais difícil a compreensão. Para meus estudos foi muito importante". "A atividade prática proposta, apesar de um pouco trabalhosa, às vezes, foi fundamental, para o meu entendimento em relação aos exercícios da atividade 4, sem ela ficaria extremamente complicada a compreensão. O e-book da unidade 4, por si só, não foi suficiente". "Sem a planilha eu não teria tirado 10 na N2, obrigada pela planilha!!!!".

\section{CONSIDERAÇÕES FINAIS}

Esse estudo teve como objetivo estudar os efeitos da implantação de planilhas eletrônicas como ferramenta de ensino em uma disciplina de estatística oferecida na modalidade EaD. Para tanto, analisou-se uma alteração na modelagem da disciplina de estatística para gestores, na qual a estrutura de uma das unidades da disciplia foi alterada com a implementação de uma planilha eletrônica. Os resultados apresentados mostraram a efetividade do uso da planilha eletrônica, por meio da opinião dos discentes da disciplina. Além disso, a ferramenta possibilitou o aumento da interação entre docentes e discentes, cujo processo comunicacional promoveu a elevação do engajamento e melhoria da performance individual, propiciando a diminuição da Distância Transacional.

$\mathrm{Na}$ Educação a Distância é fundamental discutir sobre a distância psíquica e comunicacional e não somente sobre a distância geográfica. Foi apresentada uma modelagem de artefato pedagógico ajustado, visando estabelecer a proximidade comunicacional par reduzir a distância transacional. Considerando a relação entre os elementos da distância transacional: estrutura, diálogo e autonomia do ponto de vista da percepção dos estudantes da disciplina de Estatística para gestores.

Ressalte-se também que as premissas da distância transacional, mesmo não sendo um assunto recente, ainda é desconhecido pelos atores da educação a distância. sempre ser aprofundada, revista e melhorada, de acordo com as necessidades sociais que surgem pela própria dinamicidade do saber. Como sugestões para futuras pesquisas, indicam-se a ampliação do estudo em diferentes IES e disciplinas, com o objetivo de atestar a efetividade da ferramenta em outros contextos.

\section{REFERÊNCIAS:}

BORBA, M.C.; PENTEADO, M.G. Informática e Educação Matemática. Belo Horizonte: 
Autêntica, 2005.

Chong, C. k ., Puteh M. .\& Goh S. C. (2013). Integration of Spreadsheet into the Teaching and. Learning of Financial Mathematics. Chee-Keong Chong chongck@utar.edu.my.Faculty of Business \& Finance. 3612013_20278

Dania, A. \& Posey C. (2012). Accounting Students Opinions towards use of Spreadsheets as an Instructional Tool. Journal Of Business, Industry, and Economics. Vol. 17.

Lorençatto, M. \& Carvalho, M. J. S. (2011). A distância transacional e a percepção de estudantes. CINTED-UFRGS. Novas Tecnologias na Educação. Vol. 9 № 2.

Minayo, M. C. de S. (1994) Pesquisa Social: teoria, método e criatividade. Petrópolis, RJ: Vozes.1994

Moore, M. (1993) Theoretical Principles of Distance Education. London: Routledge, p. 22-38

Moran, J. M. (2015). Mudando a educação com metodologias ativas. Souza, C. A e Morales, O. E. T. (orgs.). PG: Foca Foto-PROEX/UEPG. P. 15-32

Phungsuk, R., Viriyavejakul, C. \& Ratanaolan, T. (2017). Development of a problembased learning model via a virtual learning environment. Kasetsart Journal of Social Sciences. http://dx.doi.org/10.1016/j.kjss.2017.01.001 2452-3151. Kasetsart University. Publishing services by Elsevier B.V. This is an open access article under the CC BY-NCND license. 